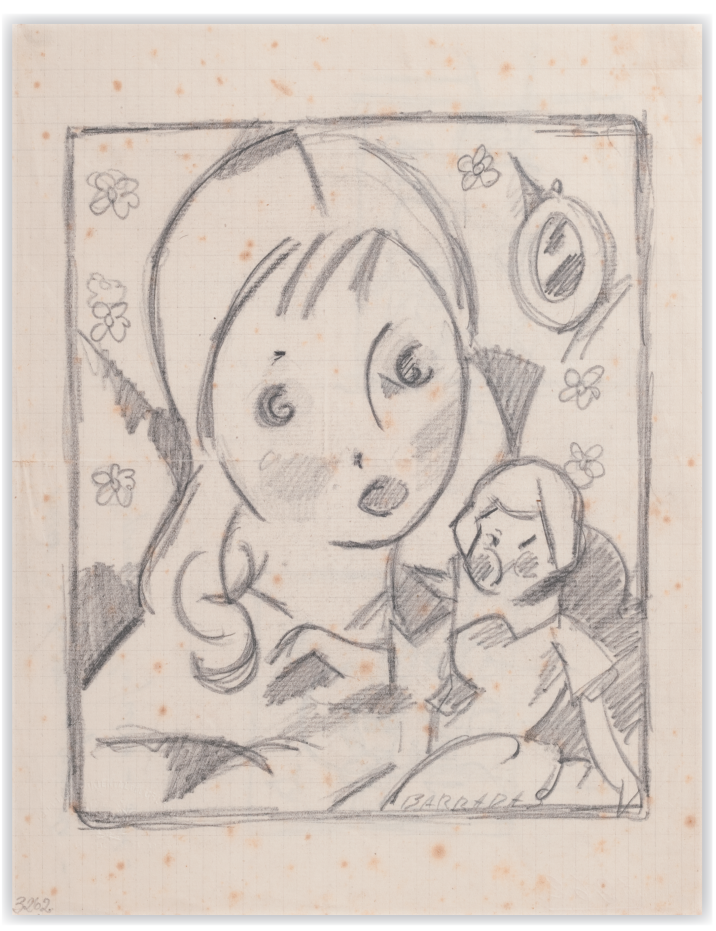

PROEMIO

\title{
Una historia posible de las infancias en América
}

En las VIII Jornadas de Historia y Cultura de América desarrolladas en la Universidad de Montevideo en julio de 2017 , se propuso una Mesa denominada Infancia, Cultura y Sociedad coordinada por el Dr. Luis Delio, la Dra. Laura Osta, y la Mag. Silvana Espiga. Fue una instancia necesaria para reflexionar y debatir históricamente el tema de la infancia y la situación de niños y niñas. En los meses siguientes se continuó el trabajo iniciado en esa reunión académica, promoviendo espacios específicos para pensar la historia de las infancias en un contexto en el que aun predominan la historia política y la económica. Los congresos de ALAS (Asociación Latinoamericana de Sociología) en diciembre de 2017 y CHIELA (Congreso Iberoamericano de Historia de la Educación) en marzo de 2018, celebrados también en 
Montevideo, ofrecieron nuevos espacios para el conocimiento de investigaciones emprendidas por diferentes países y universidades. Este rico intercambio ofreció el cauce conveniente para promover una publicación de estudios históricos referidos a las infancias en América.

La historización de las infancias viene siendo enfocada desde diversas disciplinas: la historia social de la educación, la historia de las mujeres y la familia, los derechos humanos, las políticas sociales y jurídicas, la psicología, la sociología, la antropología, los estudios literarios, la pedagogía, y -aún- la historia de la medicina y la cultura visual. Sin embargo, a nivel historiográfico, en los últimos años se advierte un recorrido propio, donde las infancias se configuran como agentes (políticos y sociales) que se visibilizan y problematizan como sujetos. Es real la necesidad de abordar las infancias desde enfoques interdisciplinares.

El estudio de las infancias implica pensarlas al menos desde tres perspectivas que se interrelacionan. En primer término, entrever las infancias como sujetos partícipes de la historia (publicidades, "señas" de niños huérfanos, pinturas, fotografías, historietas, canciones infantiles, juegos, juguetes, ropa, etc.). En segundo lugar, mostrar los discursos de los actores vinculados a niños, niñas e infancias (estudios médicos, registros pedagógicos y escolares, manuales, entre otros). Por último, rastrear su voz (diarios íntimos, cartas, declaraciones judiciales, dibujos, cuadernos escolares, fotografías, entre otros). Pensar las fuentes a partir de nuevas preguntas se transforma en un desafío metodológico para los historiadores de las infancias. Es difícil encontrar los registros de las infancias: sus huellas, casi siempre mediadas por la mirada tutelada de los adultos, son escasas y dispersas. Los textos que este número de Humanidades ofrece al lector, estudios y artículos, exponen la diversidad de fuentes que se constituyen en otros tantos insumos para construir discursos históricos en este campo de estudio.

No existe una infancia, sino una idea que se construye y resignifica con infancias situadas en diversas circunstancias. Los trabajos aquí expuestos abordan el estudio de una infancia particular como problema y lo hacen desde una mirada histórica dentro de una corriente de investigación:

Es así como, por un lado, puede afirmarse que se trata de una corriente de investigación y de producción gestada y atravesada en gran medida por las preocupaciones del 
presente $[\ldots]$ resulta difícil no trazar una línea directa entre una serie de problemáticas y transformaciones políticoinstitucionales contemporáneas y el establecimiento de una agenda de investigación como la que se ha constituido en los últimos años ${ }^{1}$.

Es en este contexto, que el número de Humanidades dedicado a la historia de las infancias, se ofrece como un dinamizador de este campo específico de investigación en el Uruguay. El dossier pretende reconocer las infancias "fragmentadas" en diversos lugares de Hispanoamérica y en sus discursos. La variedad de enfoques de los autores, los diversos problemas y las líneas de trabajo seguidas ofrecen la posibilidad de un amplio recorrido conceptual.

El medio académico uruguayo no ha sistematizado aún las líneas de investigación en este nuevo campo de estudio. De todas formas, se pueden reconocer investigaciones específicas o de frontera vinculadas a temáticas como: género y educación (Rostagnol, S., Graña, F., Clavero, C., Martinis, P.), historia sociocultural (Barrán, J.P., Osta, L., Espiga, S., Rostan, E., Cosse I., Leopold, S.), cuerpo (Dogliotti, P.), minoridad, judicialidad y delincuencia (Alpini,
A., Facundo, A., Fessler, D.), manuales escolares (Bralich, J.).

El dossier incorpora trabajos elaborados por especialistas a nivel del continente; éste se estructura en tres estudios y tres artículos. El estudio de la investigadora mexicana Susana Sosenski Infancia y violencia: los robachicos en las historietas para adultos en México (1945-1950) explora, a través de la prensa, el acceso que tuvieron los niños mexicanos a las historietas para adultos. En particular, en este análisis aparece la figura del secuestrador de niños: el "robachicos". A partir de este personaje, la autora examina las diversas formas de violencia física y simbólica (entre adultos, de adultos hacia niños), y -asimismo- los aportes en la configuración de la idea de riesgo urbano transmitidas principalmente a través de la lectura de los Pepines y Chamacos. El análisis de las historietas en su lenguaje, narrativa e imágenes permite a la autora exponer los valores existentes sobre violencia, clase, género e infancia. Destaca el rol de los niños lectores como trasmisores culturales en una sociedad mayoritariamente analfabeta. Por otra parte, la autora demuestra que los niños/as fueron consumidores de lecturas que no estaban destinadas para ese público, pero que eran de fácil

\footnotetext{
Isabella Cosse, Valeria Llobet, Carla Villalta y M. Carolina Zapiola (eds.), Infancias: políticas y saberes en Argentina y Brasil (siglos XIX y XX) (Buenos Aires: Teseo, 2011), 14.
} 
consumo y acceso, lo cual incidió en la "sociabilidad infantil" y en los "procesos de identificación".

El estudio de la historiadora argentina Lucía Lionetti, Recorte fugaces de una experiencia. Ser niñas en el mundo colonial de Buenos Aires y su campaña: un enfoque micro desde las fuentes judiciales, aborda la interseccionalidad etaria, el género y el rango social a través del análisis de fuentes judiciales. A partir del trabajo en los archivos judiciales intenta aproximarse a un "universo de valores", donde la subalternidad de niños y niñas es dada por su condición de sexo y edad. La niñez es representada en una situación de pre-individuación, condicionada a la prolongación de los valores del grupo, percibiendo a la infancia como experiencia no universal. Desarrolla detalladamente el proceso judicial de tres casos de niñas marcadas por la violencia (estupro). Esto le permite aproximarse a un sistema de valores, a un orden social, y a la caracterización de los castigos físicos en su relación con la concepción del cuerpo. La fuente judicial para Lionetti "evoca el conflicto, la ruptura y es elocuente para describir el mundo de valores", experiencias límites e intimidades, un fragmento fugaz en la vida de niños y niñas.

El tercer estudio, escrito por el historiador chileno Jorge Rojas,
Internación, experimentación pedagógica $y$ vivencias en el Politécnico Elemental de Menores Alcibiades Vicencio. Chile, 1929-1974, analiza el Politécnico de menores de San Bernardo creado en 1928 (Chile), y el sistema de internado. En este espacio observa las relaciones de cooperación, conflicto y construcción de identidades. Rojas señala que el sistema de internado no suponía un encierro total y los internos no pueden ser considerados como simples receptores de los procesos de institucionalización. A partir de las lecturas de fuentes discontinuas en el tiempo por la intervención militar, tales como: reportajes periodísticos, informes de boletines institucionales, documentación inédita (de archivos ministeriales), planos, periódicos escolares del Politécnico y fotografías, periodiza y caracteriza cuatro décadas de esta institución. Este artículo tiene el mérito de ser el primer estudio realizado sobre el Politécnico chileno, destacando a nivel metodológico el uso de las fuentes para reconstruir una historia institucional y las tensiones entre memoria e historia. Una microhistoria forjada y limitada dentro del Politécnico, donde -como expresa el autor- las "relaciones de poder entre el estamento directivo y técnico, así como las que surgieron entre los propios muchachos con un perfil tan heterogéneo, dieron vida a una micro-sociedad que 
experimentó en varios momentos los efectos lejanos de la historia que se estaba viviendo afuera".

El investigador colombiano Absalón Giménez Becerra en su artículo Los tiempos de la infancia en Colombia a través de la transformación del juego y el juguete a finales del siglo XX e inicios del XXI, parte de un enfoque genealógico e histórico donde señala algunas cuestiones que permiten reflexionar y reconocer los valores y significaciones que la sociedad le da al juego y a los juguetes. El autor parte de la idea de que "la familia constituyó una nueva tecnología política sobre el cuerpo infantil", en la que las prácticas no discursivas (como el juego) modificaron las formas vinculares hacia los niños. El juego y la transformación del juguete serían bajo esta óptica elementos constitutivos de la subjetividad infantil. Para Giménez, el juego se convierte en un espacio de libertad y de formación del sujeto (infancia). A su vez, aborda las implicancias psicológicas y del desarrollo sociocognitivo que tienen los juguetes para los niños y las niñas, observando la repercusión que alcanzó en Colombia la llegada de los juguetes extranjeros. El imaginario de infancia cambia en relación con la transformación del juguete, en un proceso que puede ser historiado.
El artículo de la investigadora uruguaya Carolina Clavero, Ana Armand Ugon y la formación del sujeto "niñas" en las Escuelas del Hogar, es un trabajo de historia social de la educación desde la perspectiva de género. La autora se centra en el análisis de las Escuelas del Hogar de Colonia Valdense, tomando como documento principal el texto 'Libro de cocina y organización doméstica" de la maestra Ana Armand Ugon (1925). Se destaca en este artículo el empleo de un tipo de fuente poco utilizada en los análisis históricos: los manuales de cocina. La autora compara algunos aspectos del contenido del libro de cocina en sus ediciones de 1925, 1933 y 1957. Observa los cambios en la tecnificación del hogar, la modificación de las pautas alimentarias y los fundamentos de la educación de las mujeres. El ahorro, la economía doméstica y la religión eran pilares de ese modelo de educación. Clavero destaca la peculiaridad del libro de Armand Ugón, ya que vinculaba la tarea doméstica con una profesión productiva, y asociada a valores espirituales y de salud física. Desde esta perspectiva, en el seno de una sociedad rural y agrícola, las mujeres pasaban a ocupar un lugar económico significativo profesionalizando las tareas domésticas. 
El tercer artículo, realizado por la historiadora uruguaya Silvana Darré, se titula $A$ sesenta años del psiquismo fetal. La infancia como portal. Este trabajo permite pensar en la configuración y comprensión de la historia de la infancia desde los aportes de las teorías psicológicas y de qué manera estas teorías se presentan como un nodo entre la historia de la humanidad y el desarrollo del individuo. Desde una perspectiva diferente a la de los otros autores, Darré recopila de manera sintética las teorías de Haeckel, De Mause, Rank y Rascovsky. Pone en discusión y hace dialogar a las construcciones teóricas del psiquismo de las etapas prenatales, desde las ideas de ontogenia y filogenia. Centra su análisis en los aportes de Rascovsky, hacia finales de los años 50 del siglo $\mathrm{XX}$, quien explicaba una variante del paradigma biogenético. El objetivo del trabajo es presentar a la infancia como "un portal para el conocimiento de la especie" y el "pensamiento de frontera (ocultismo, espiritualidad, esoterismo)".

Las coordinadoras de este número agradecemos a la Universidad de Montevideo y en especial al Dr. Fernando Aguerre y a la Dra. Carolina Cerrano, quienes apoyaron la propuesta de este estudio; asimismo, a los evaluadores y a los investigadores que generosamente respondieron a la convocatoria de la revista Humanidades.

Dra. Laura Osta Universidad de Montevideo / Investigador ANII-Nivel 1 lauraosta@hotmail.com ORCID iD: https://orcid.org/0000-0002-6683-5604

Mag. Silvana Espiga Doctoranda en Educación (FHCE) CFE-ANEP/ FLACSO-Uruguay silvanaespiga@gmail.com ORCID iD: https://orcid.org/0000-0003-3970-8033 